\title{
Pretreatment of agriculture field water for improving membrane flux during pesticide removal
}

\author{
Romil Mehta $^{1}$ N. K. Saha ${ }^{1}$ A. Bhattacharya ${ }^{1}$
}

Received: 15 March 2016/Accepted: 7 September 2016/Published online: 23 September 2016

(C) The Author(s) 2016. This article is published with open access at Springerlink.com

\begin{abstract}
Pretreatment of feed water to improve membrane flux during filtration of agriculture field water containing substituted phenyl urea pesticide diuron has been reported. Laboratory-made reverse osmosis membrane was used for filtration. Preliminary experiments were conducted with model solution containing natural organic matter extracted from commercial humic acids, divalent ions $\mathrm{Ca}^{2+}, \mathrm{Mg}^{2+}$. Membrane fouling was characterized by pure water flux decline, change in membrane hydrophilicity and infrared spectroscopy. Natural organic matter present in field water causes severe membrane fouling. The presence of divalent cations further aggravated fouling. Use of ethylenediaminetetraacetic acid (EDTA) and polyacrylic acids (PAA) in feed resulted in the decrease in membrane fouling. Pretreatment of field water is a must if it is contaminated with micro-organism having membrane fouling potential. Feed water pretreatment and use of PAA restricted membrane fouling to $16 \%$ after $60 \mathrm{~h}$ of filtration. Membrane permeate flux decline was maximum at the first $12 \mathrm{~h}$ and thereafter remained steady at around $45-46 \mathrm{~lm}^{-2} \mathrm{~h}^{-1}$ till the end of $60 \mathrm{~h}$. Diuron rejection remained consistently greater than $93 \%$ throughout the experiment. Diuron rejection was found to be unaffected by membrane fouling.
\end{abstract}

Keywords Fouling · Pesticide · Pretreatment - Reverse osmosis $\cdot$ Natural organic matter

N. K. Saha

nsaha@csmcri.org

1 Reverse Osmosis Division, CSIR-Central Salt and Marine Chemicals Research Institute, Gijubhai Badheka Marg, Bhavnagar, Gujarat 364 002, India

\section{Introduction}

Substituted phenyl urea herbicides are most widely used pesticides in agriculture and aquaculture. Diuron has been identified as the third most frequently found hazardous pesticide in ground water having adverse impact on natural resources (Newman 1995). The maximum permissible concentration of diuron in drinking water in USA is $10 \mu \mathrm{g} /$ 1 , and the norm is even stricter in Europe with maximum permissible limit of total pesticides and related product content in drinking water being $0.5 \mu \mathrm{g} / \mathrm{l}$ (Field et al. 1997; Plakas and Karabelas 2012). Conventionally, these are removed from water by activated carbon, ozonation and peroxide treatment (Agbekodo et al. 1996; Cyna et al. 2002). The presence of natural organic matter in water limits the removal efficiency of such pesticides from water by conventional methods. Moreover, stringent directives from governments and occasional high organic load in water often challenge the efficiency of these methods to meet the drinking water standard. Additional treatment adds further cost to already expensive methods (Devitt et al. 1998). In many occasions, pesticides are only partially removed after secondary and even tertiary treatment in treatment plants (Campo et al. 2013). In that way, the treatment plants were pointed out as source of pesticide contaminants. Membrane filtration has been envisaged as an alternative to these conventional water treatment methods for pesticides removal. There are several reports on use of commercial membranes capable of removing pesticides more than $90 \%$ from water. In a recent publication pesticide removal was reported in the range of 92-98 \% by laboratory-made reverse osmosis membrane (Mehta et al. 2015) and there is a continuous effort put by the membrane researchers to push this value to even higher level. 
Membrane fouling is the major constraint associated with membrane filtration. Natural organic matters (NOM) are well-known membrane foulants (Cho et al. 1999; Tang et al. 2007). Different factors namely membrane properties, feed chemistry, NOM characteristics and operating conditions influence membrane fouling in the presence of NOM (Al-Amoudi 2010). The nature of NOM is also an important factor determining extent of membrane fouling. The hydrophobic fraction of NOM was reported to be the major membrane foulant causing flux decline. The extent of NOM fouling is also dependent on solution chemistry and NOM molecular weight. Membrane flux decline has also been reported during pesticide removal (Mehta et al. 2015). Extensive flux decline was reported when ground or surface water containing NOM was membrane treated (Van der Bruggen et al. 1998, 2001). During rain, the excess NOM load often escalates the problem (Cyna et al. 2002). Extensive pretreatment and pre-filtration are required to maintain plant operation at desired level and permeate water quality.

Interestingly, the presence of NOM in feed water does not have always negative effect on membrane pesticide rejection. Pesticide rejection in the presence of NOM mostly depends on membrane properties, nature of pesticides, interaction between NOM and pesticides, ionic environment (Agbekodo et al. 1996). In most of the studies, pesticide rejection was reported to increase in the presence of NOM (Agbekodo et al. 1996; Boussahel et al. 2002; Dalton et al. 2005; Devitt et al. 1998; Drewes et al. 2004; Plakas and Karabelas 2009) with some exception for diuron (Boussahel et al. 2000). For a tight pore reverse osmosis membrane, no significant effect of NOM on diuron rejection was observed (Mehta et al. 2015).

Although there are several reports describing the adverse effect of NOM fouling on membrane performance, reports on effect of the same during pesticide removal is very less and, particularly on membrane flux is rare. Benitez et al. (2009) studied the effect of different parameters on permeate flux during pesticide removal from ultrapure water using UF and NF membranes. Membrane flux decline was reported during atrazine filtration from pure water (Ahmad et al. 2008) by different nanofiltration membranes but there was no report on flux restoration or fouling mitigation. The presence of natural organic matter in ground or agriculture field water is a very common phenomenon. Therefore, the situation may be expected to be more complicated in real scenario.

In our earlier publication (Mehta et al. 2015), we have reported that diuron and isoproturon rejection was unaffected by the presence of humic acid in feed water. However, a steady flux decline was observed when feed was prepared with water collected from agriculture field.
The present work aims to improve membrane flux during pesticide removal from agriculture field water. Membrane fouling during the process was investigated and pretreatment strategies to mitigate membrane fouling have been reported. Experiments were carried out using a laboratory-made RO membrane using model solutions and water collected from agriculture field as feed.

\section{Experimental}

\section{Materials}

Polysulfone (PS) (Udel P 3500 NT LCD) of high molecular weight was purchased from Solvay Specialities India Private Limited, Panoli, India. Solvent used for PS, N,Ndimethylformamide (DMF) was purchased from MerckMillipore India. Polyester fabric used as support for casting PS ultrafiltration membrane was purchased from PGI, France. Meta (1, 3)-phenylene diamine (MPD), trimesoyl chloride (or 1, 3, 5-benzenetricarbonyl trichloride, TMC), the two monomers used for thin film coating were purchased from Acros Chemicals and Sigma-Aldrich, respectively. Phenyl urea pesticides diuron and technical grade humic acid, poly (acrylic acid sodium salt) of molecular weight $\sim 5100 \mathrm{Da}$ and dialysis bag of molecular weight cut-off 12,000 Da were also purchased from SigmaAldrich. EDTA disodium dehydrate (EDTA: Ethylenediaminetetraacetic acid) was purchased from Finar limited, Ahmedabad, India. Hexane used to dissolve TMC was purchased from Ranbaxy, India. Distilled water was used as solvent for MPD. Sodium chloride, calcium sulfate, magnesium sulfate used to estimate membrane performance were purchased from SRL, India and sodium lauryl sulfate (SLS) from Qualigens Fine Chemicals Mumbai, India. Field water was collected from well in agriculture field located in nearby village.

\section{Methods}

\section{Membrane preparation}

Polysulfone membrane was prepared following the principle of phase inversion. $15 \%(\mathrm{w} / \mathrm{w})$ PS solution in DMF was cast on polyester fabric under controlled condition using a semiautomatic casting machine. Casting speed was maintained by the computerized program and casting thickness was maintained by lifting casting blade above the fabric up to a specified height using a pair of micrometers attached at the two ends of casting blade. Polysulfone membrane, thus, prepared was used for polyamide thin film coating. The active side of the membrane was coated by carrying out interfacial polymerization reaction between 
MPD and TMC. Thin film composite (TFC) membranes were prepared at A4 size scale. This was thoroughly washed with citric acid and water to ensure removal of unreacted monomers. Thin film composite membrane, thus, prepared was glycerol coated for storage till further use. TFC membranes used in this study displayed $95 \pm 0.5 \%$ sodium chloride rejection under standard test condition. Details of membrane preparation conditions are described in (Mehta et al. 2015; Saha and Joshi 2009).

\section{Membrane performance evaluation}

Membrane performance was evaluated in test kit comprising of four test cells in series in cross-flow mode. The effective filtration area for each membrane disc was $15.19 \mathrm{~cm}^{2}$. Membrane discs were pressurized at $2.07 \mathrm{MPa}$ pressure for $30 \mathrm{~min}$ before recording the flux data at $1.38 \mathrm{MPa}$ pressure. More information on membrane testing kit and set-up can be found in (Mehta et al. 2015). Pure water flux (PWF) and feed water flux were measured for all membrane discs. Rejection of feed components was calculated following the equation written below:

$R(\%)=\left(1-\frac{C_{i, \mathrm{p}}}{C_{i, \mathrm{f}}}\right) \times 100$

where $C_{\mathrm{p}}$ and $C_{\mathrm{f}}$ are concentration of component $i$ in permeate and feed, respectively.

Membrane flux was determined in terms of volume of permeate collected per unit time and per unit membrane active area and expressed in $1 \mathrm{~m}^{-2} \mathrm{~h}^{-1}$. Average of all four membrane discs data has been calculated and reported in this work.

Membrane test kit was operated for $12 \mathrm{~h}$ if otherwise not mentioned continuously to determine change in membrane flux at every hour. Since the experiments were carried out in continuation to the work published earlier filtration experiments were designed for $12 \mathrm{~h}$ (Mehta et al. 2015). PWF was determined at the beginning and after completion of 12-h filtration experiment. Membrane fouling was expressed as the ratio of difference in pure water flux measured before and after membrane fouling to pure water flux before membrane fouling.

\section{Feed preparation}

If otherwise not mentioned feed solution was prepared always using deionized (DI) water. Concentrated diuron solution was prepared in methanol and stored in refrigerator. Standard solution of diuron in water was prepared by transferring small proportion of the methanol solution and subsequently diluting the same with DI water.

The high molecular weight fraction of humic acid was used as representative natural organic material (NOM) in model solution. The commercial humic acid sample was purified by repeatedly precipitating and dissolving the same in strong acidic and strong basic medium. First the humic acid sample was dissolved in DI water at $\mathrm{pH} 10$ maintained by adding sodium hydroxide solution $(10 \mathrm{M})$ dropwise. To this solution, hydrochloric acid (1 M) was added dropwise. Precipitation occurred when $\mathrm{pH}$ of the solution dropped down to 3. This suspension was then centrifuged at 10,000 rpm for $10 \mathrm{~min}$. After centrifugation, the supernatant was discarded and the precipitate was dissolved in DI water at $\mathrm{pH} 10$ again. This process of precipitation and dissolution was repeated for six times. In the final step, the precipitate was dissolved in DI water at $\mathrm{pH} 10$ and the solution $\mathrm{pH}$ was neutralized by adding $\mathrm{HCl}$ dropwise. The neutral solution of humic acid purified fraction was then transferred to dialysis bag of $12,000 \mathrm{Da}$ and was dialysed against DI water. The water was replaced every $12 \mathrm{~h}$. When the conductivity change of the dialysis solution was less than $1 \mu \mathrm{S}$ and no color change was observed, the process was considered completed and it took 10 days. Finally, the dialyzed suspension was fridge dried to obtain the high molecular weight fraction of the commercial humic acid.

\section{Analytical methods}

Instrumental technique The contact angle measurement instrument from Kruss (Germany) and DSA10 software were used to estimate membrane surface hydrophilicity/ hydrophobicity by sessile drop contact angle method. An average of ten contact angle measurements at different locations using HPLC grade water has been reported. IR spectra of membrane were recorded using Agilent CARY620 FTIR microscope. A total of 32 scans were performed at $4 \mathrm{~cm}^{-1}$ resolution at ATR mode using ZnSe crystal to characterize membrane surface. Zeta potential of Solution containing NOM, diuron and cations was measured using Malvern Zetasizer Nano ZS90. The quartz cuvettes used to place the solutions were thoroughly washed with DI water followed by sample solution. Diuron in feed and permeate was quantified using GPC following the method described in (Mehta et al. 2015).

Microbial growth analysis Microbial presence in field water and different membrane samples was established by the following method. $28 \mathrm{gm}$ of nutrient agar $(1.5 \%)$ was dissolved in $1000 \mathrm{ml}$ of DI water to prepare the growth media. The media and the petri dishes used in the study were autoclaved. $25 \mathrm{ml}$ of media was added to each petri dish and allowed to solidify for $20 \mathrm{~min}$ in laminar air flow. Samples of field water and ultrafiltered field water $(100 \mu \mathrm{l}$ each) were spread on the solidified media present in petri dish. Similarly the active side of the membrane samples 
were placed on the petri dish facing the media. These petri dishes either containing samples of water or membrane were incubated at $30{ }^{\circ} \mathrm{C}$ for 3 days for possible microbial growth.

\section{Results and discussion}

\section{Filtration of diuron in model solution}

Since agriculture field water contains NOM, divalent ions and pesticides, model solutions were prepared in DI water adding high molecular weight fraction of humic acid as representative NOM, divalent salts either in combination or individually. Diuron was added to all these solutions. Concentration of NOM in feed water wherever added was maintained at $100 \mathrm{ppm}$ and that of diuron was kept at $2 \mathrm{ppm}$. The concentrations of feed components were consciously chosen to keep feed property similar to that of field water. The characteristics of field water were determined several times and the characteristics remained very similar to the one published earlier (Mehta et al. 2015). Pesticide concentration employed was kept high intentionally to match the concentration kept in earlier publication (Mehta et al. 2015). The high concentration of pesticide was considered to test membrane performance at extreme conditions. Additionally the high concentration of pesticide facilitated instrumental analysis of pesticide concentration. Continuous flux decline was recorded throughout the filtration period. Membrane fouling (14\%) was more than double the value $(<6 \%)$ recorded with diuron alone in DI water (Mehta et al. 2015). Total permeate flux decline was $14 \%$ at the end of $12 \mathrm{~h}$. This indicates NOM extracted from commercial humic acid fouled the membrane and have adverse effect on membrane performance. Visual inspection indicated deposition of feed component on membrane surface. The water contact angle value showed increase in contact angle from 65 to 75 indicating hydrophobic nature of deposited NOM. Nilson and DiGiano (1996) also reported similar observation made on effect of NOM composition on nanofiltration membrane performance. The high molecular weight hydrophobic fraction of NOM was reported to be more fouling in nature. In this study, the NOM fraction used in feed represented molecular weight $\geq 12,000 \mathrm{Da}$. Addition of calcium and magnesium to the feed containing NOM and diuron worsened the situation further. Figure 1 compares the effect of the presence of divalent ions in feed water on membrane flux during diuron filtration. Figure 2 shows the effect of addition of calcium and magnesium to feed on membrane fouling. Concentration of calcium and magnesium was chosen on the basis of their concentration actually present in field water. Membrane fouling was

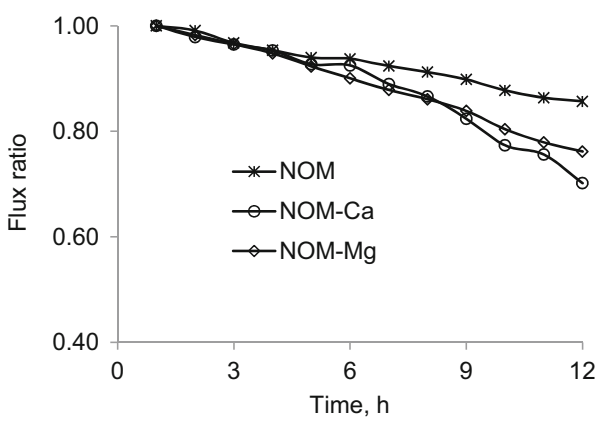

Fig. 1 Effect of the presence of divalent ions in feed on membrane flux during diuron filtration. Concentration of calcium and magnesium are 80 and $125 \mathrm{ppm}$, respectively. Flux ratio is permeate flux/ permeate flux at $1 \mathrm{~h}$

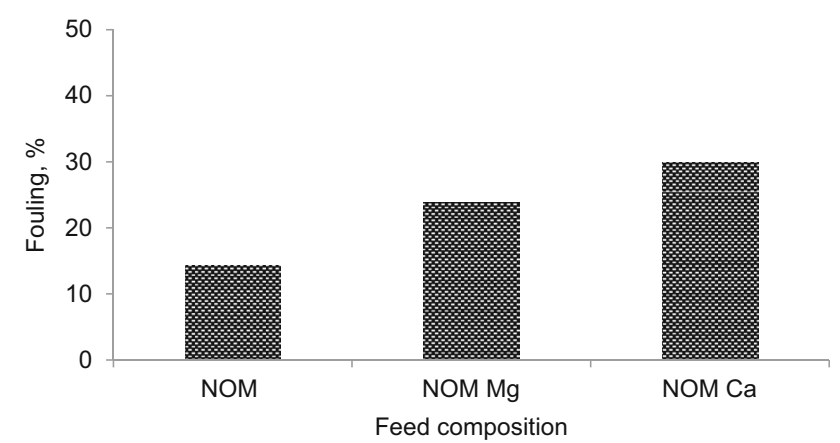

Fig. 2 Effect of the presence of divalent ion in feed on membrane fouling during diuron filtration. Concentration of calcium and magnesium are 80 and $125 \mathrm{ppm}$, respectively

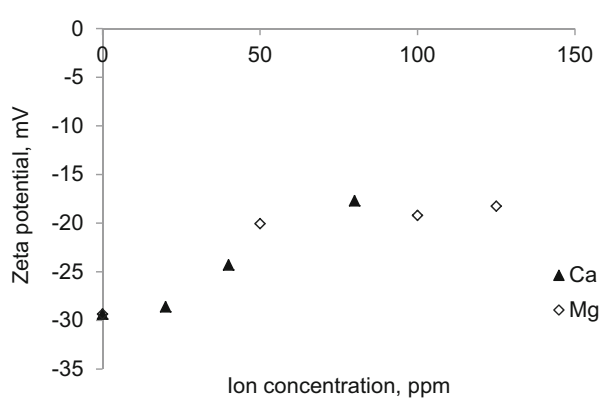

Fig. 3 Effect of ion concentration and type on feed solution zeta potential. At zero concentration of ions feed contained NOM and diuron only

estimated after $12 \mathrm{~h}$ of filtration experiment. In comparison to NOM only case, irrespective of ion types membrane fouling increased further on addition of divalent ions to feed. It is important to mention that experiment was carried out at $\mathrm{pH}$ 7. Solution zeta potential becomes less negative with increase in divalent ion concentration (Fig. 3). Zeta potential was maximum when NOM and diuron were only present in feed and minimum at the concentrations of cations used in this study for flux measurement. This shows that the NOM fraction extracted from humic acid is 
negatively charged and indicates the presence of functional groups which were deprotonated at even $\mathrm{pH}$ 7. Zeta potential of solution decreased on addition of divalent cations may be due to the formation of cations-NOM complex. The membrane used in this work should also be negatively charged at $\mathrm{pH} 7$ as reported by Singh et al. (2011). Hong and Elimelech (1997) reported that membrane surface becomes increasingly less negative with the increase in divalent ion concentration in feed in basic medium due to charge shielding and adsorption of cations on specific functional groups present on membrane surface. Therefore, reduced charge interaction between membrane and cation-NOM complex enhanced membrane fouling by NOM as observed in the present study when cation were added to feed. Calcium ion is also reported to decrease solubility of humic acid (Choe et al. 1986) and also can form bridge between the negatively charged groups of humic acid and membrane surface. Therefore, the presence of NOM and divalent cations in feed which are very much probable component of actual field water is severely fouling membrane and restricting the application of membrane filtration to remove pesticides from water.

\section{Fouling mitigation}

To mitigate membrane fouling during pesticide removal from agriculture field water, it was realized that divalent cations present in field water must be captured so that their interaction with NOM may be minimized. Decreased free cation concentration in feed water should also help in maintaining membrane negative charge and the same on NOM. Additionally experiment $\mathrm{pH}$ at basic range should also discourage membrane fouling by NOM through charge interaction. Therefore, further experiments were conducted at basic $\mathrm{pH}$ and in presence of ion scavengers as reported in the subsequent sections.

\section{Effect of addition of EDTA}

Ethylenediaminetetraacetic acid (EDTA) is an effective metal ion chelating agent. Addition of EDTA was reported to reduce membrane fouling by complex formation with calcium ion thereby reducing the availability of free calcium ions to interact with humic acid (Hao et al. 2011). It has also been reported that EDTA decomposes humic acidcalcium complex to extract $\mathrm{Ca}^{2+}$. The effects of addition of EDTA at different concentrations and $\mathrm{pH}$ on membrane permeate flux and membrane fouling are shown in Fig. 4a and $b$, respectively. To keep close proximity to natural field water condition feed solution was prepared in DI water containing diuron (2 ppm), NOM (100 ppm), calcium sulfate $(80 \mathrm{ppm})$ and magnesium sulfate $(125 \mathrm{ppm})$. Figure $4 \mathrm{a}$ and $\mathrm{b}$ also compares membrane performance when
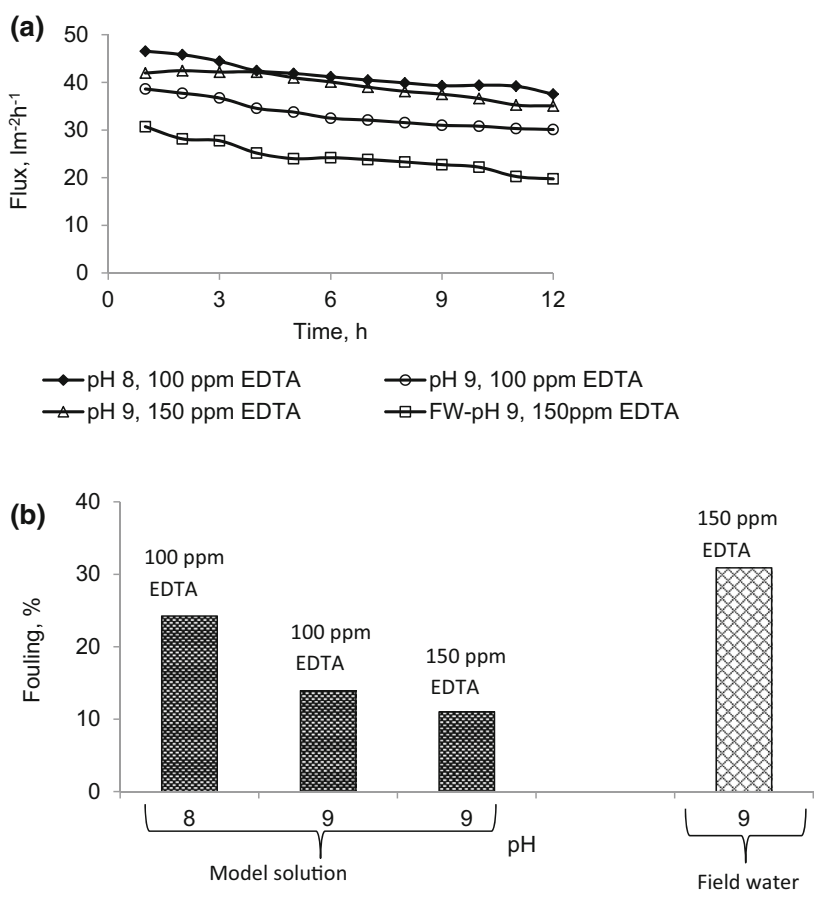

Fig. 4 Effect of addition of EDTA on a membrane flux; $\mathbf{b}$ on membrane fouling; figures compare effect of variation in $\mathrm{pH}$ of solution (pH8 and pH9) and EDTA concentrations (@ pH9, EDTA concentrations 100 and $150 \mathrm{ppm}$ ); finally the effect of EDTA addition to field water (FW) is also shown (@ pH9, 150-ppm EDTA)

model solution and actual field water were used. In comparison to the feed containing NOM and $\mathrm{Ca}^{2+}$ only membrane performance improved in terms of flux and fouling when EDTA was added to the model solution. Membrane permeate flux decline was $17-23 \%$ (Fig. 4a) and membrane fouling was restricted within $24 \%$ (Fig. 4b). For same concentration of EDTA (100 ppm), membrane fouling was reduced further when $\mathrm{pH}$ of the feed solution was increased from 8 to 9 . On the other hand, increase in EDTA concentration keeping the $\mathrm{pH}$ value fixed resulted in additional reduction in membrane fouling. Permeate flux drop was also minimum. Therefore, addition of EDTA in feed with final concentration $150 \mathrm{ppm}$ and $\mathrm{pH}$ adjusted to 9 was envisaged as a tool to control fouling during field water filtration. Surprisingly even after adjusting $\mathrm{pH}$ and increasing EDTA concentration membrane permeate flux decline (35\%) and membrane fouling (31\%) was found to be much higher during field water filtration (Fig. 4a, b). This indicated that the composition of field water and that of model solution were largely different. One strong difference exists in the fact that the model solution was prepared in DI water. Physical inspection of the membrane disc indicated slimy layer formation on membrane surface once field water was filtered. This led to the doubt of biofouling on membrane surface (Drews 2010). Microbial assay to check biological contamination 
Fig. 5 Microbial growth a in field water sample; $\mathbf{b}$ membrane sample after field water filtration; c membrane sample after field water filtration in presence of diuron, EDTA; d field water sample after ultrafiltration
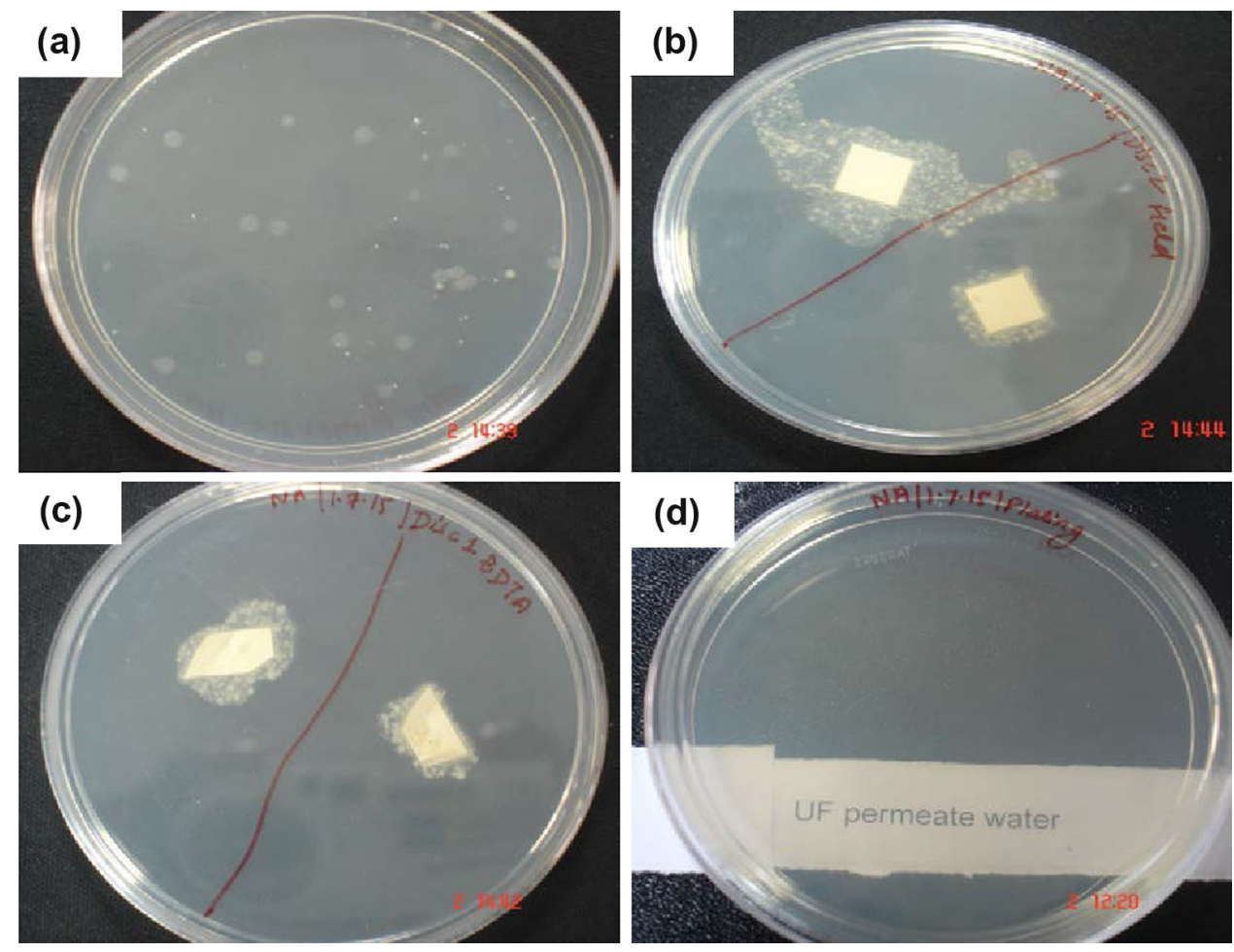

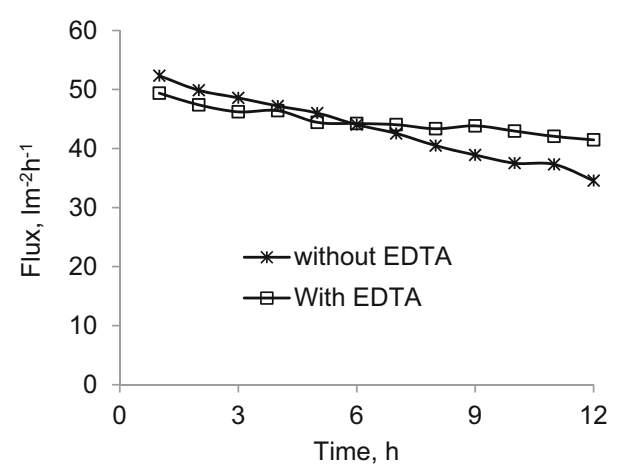

Fig. 6 Membrane flux with ultrafiltered field water

confirmed the presence of microbes in filed water as well as in fouled membrane samples. Therefore, to prevent biofouling, field water was filtered through the ultrafiltration membrane which was originally used as support for the reverse osmosis membrane reported in this study. Figure 5 shows microbial growth in untreated field water, on membrane surface after field water filtration (Fig. 5 a-c) and removal of all microbes in field water after ultrafiltration(Fig. 5d). Figure 6 compares membrane permeate flux with diuron in ultrafiltered field water as feed with and without EDTA added to it. When no EDTA was added membrane permeate flux decline was $33 \%$ which was higher than membrane flux decline observed during NOM and diuron alone in DI water case $(14 \%)$. When EDTA was added to ultrafiltered field water membrane permeate flux decline was reduced to $16 \%$ and membrane fouling was reduced to $15 \%$ compared to $35 \%$ flux decline and $31 \%$ membrane fouling with unfiltered field (Fig. 4) water after $12 \mathrm{~h}$ of filtration. Ultrafiltration of field water improved membrane performance by subsiding microbial fouling and the use of EDTA as divalent cation scavenger significantly reduced membrane fouling and flux decline during pesticide removal from field water.

\section{Effect of addition of polyacrylic acid}

Using polyacrylic acid (PAA) as metal ion binder, successful removal of divalent cation $\mathrm{Ca}^{2+}$ by microfiltration was reported by Volchek et al. (1993). Removal was maximum at $\mathrm{pH} \geq 9$. At higher $\mathrm{pH}$, the carboxylic groups of PAA get deprotonated and bind more number of free $\mathrm{Ca}^{2+}$ ions. In the present case, addition of PAA to ultrafiltered field water improved membrane performance significantly. 100-ppm PAA was added to ultrafiltered field water containing 2-ppm diuron. $\mathrm{pH}$ of the solution was maintained at 9. Observed permeate flux drop was only $4 \%$ after $12 \mathrm{~h}$ filtration. Membrane fouling was less than $5 \%$. Therefore, addition of PAA instead of EDTA improved membrane performance even further. To check the effect of addition of PAA on membrane performance over a longer period, filtration experiments were conducted for $60 \mathrm{~h}$ under similar conditions with ultrafiltered field water with and without PAA added to it. 2-ppm diuron was added to both the feeds; $\mathrm{pH}$ was maintained at 9. Flux was 


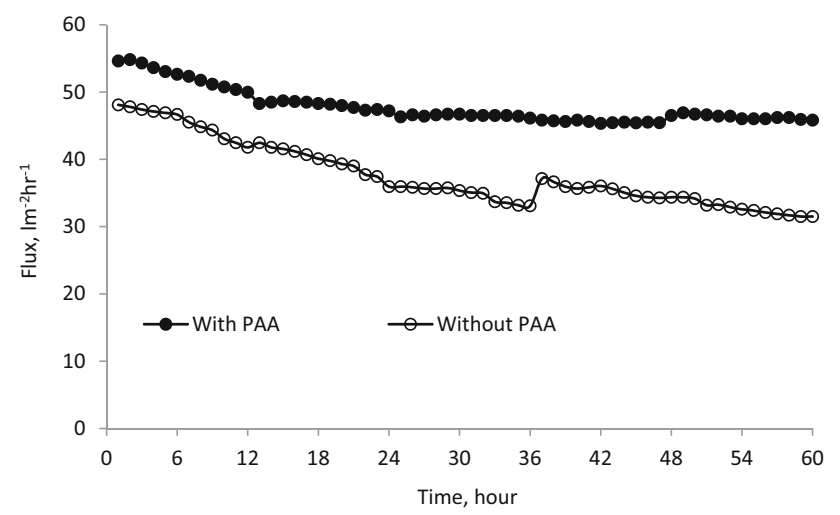

Fig. 7 Effect of addition of PAA to field water on membrane permeate flux

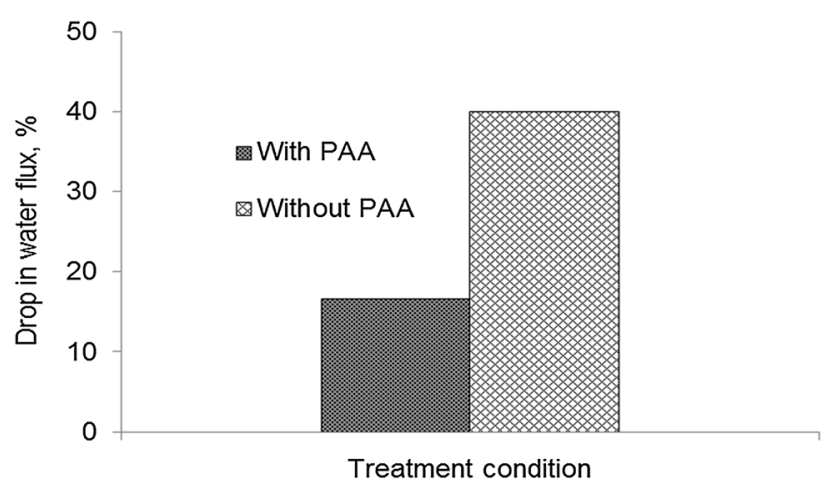

Fig. 8 Effect of addition of PAA to field water on membrane pure water flux

measured at every hour. Filtration was continued for $12 \mathrm{~h}$ a day. PWF was measured before the start and after completion of filtration experiment. Figure 7 compares membrane permeate flux over 60-h period for field water with and without PAA added to it. Permeate flux decline was higher $(33 \%)$ for feed containing no PAA than feed containing PAA $(16 \%)$. Permeate flux remained almost steady for feed containing PAA during 13th to 60th hour filtration experiment whereas there was a continuous flux decline observed when no PAA was added. Figure 8 shows drop in pure water flux measured after $60 \mathrm{~h}$ of filtration experiment. Pure water flux measurement shows higher membrane fouling $(40 \%)$ for feed containing no PAA than feed containing PAA $(17 \%)$. Visual inspection of the membrane discs after $60 \mathrm{~h}$ of filtration experiments suggests deposition of feed components on the membrane surface (Fig. 9). Visibly deposition was more in case of feed containing no PAA (Fig. 9a) than feed containing PAA (Fig. 9e). No deposition could be observed with naked eye in the center part of all the discs (encircled).

Figure 9 also shows the representative shape of water droplet when deposited on membrane surface. Water contact angle was measured in different positions located around the membrane disc center (the white part of the membrane encircled in the Fig. 9a, b) and in the areas with the dark patches. In the dark part of the membrane discs, for feed water containing no PAA, contact angle measurement indicates hydrophobic nature (angle $>100$ ) (Fig. 9b) while the same for feed containing PAA indicates hydrophilic nature of the deposit (angle <55) (Fig. 9f). Measured contact angle values in the center part of the disc are very similar irrespective of the fact whether PAA was added or not to the feed (Fig. 9c, g) and was close to the pristine membrane value (Fig. 9d). Therefore, it may be assumed that no deposition took place at the center part of the membrane. It is because of the design of the test kit cells (described in (Mehta et al. 2015)) in which the feed water hits the center of the membrane disc and as a result no deposition taking place at the center of the discs.

To investigate the nature of deposition on membrane surface, infrared spectrum was recorded at ATR mode. Figure 10 displays the spectra of pristine and fouled
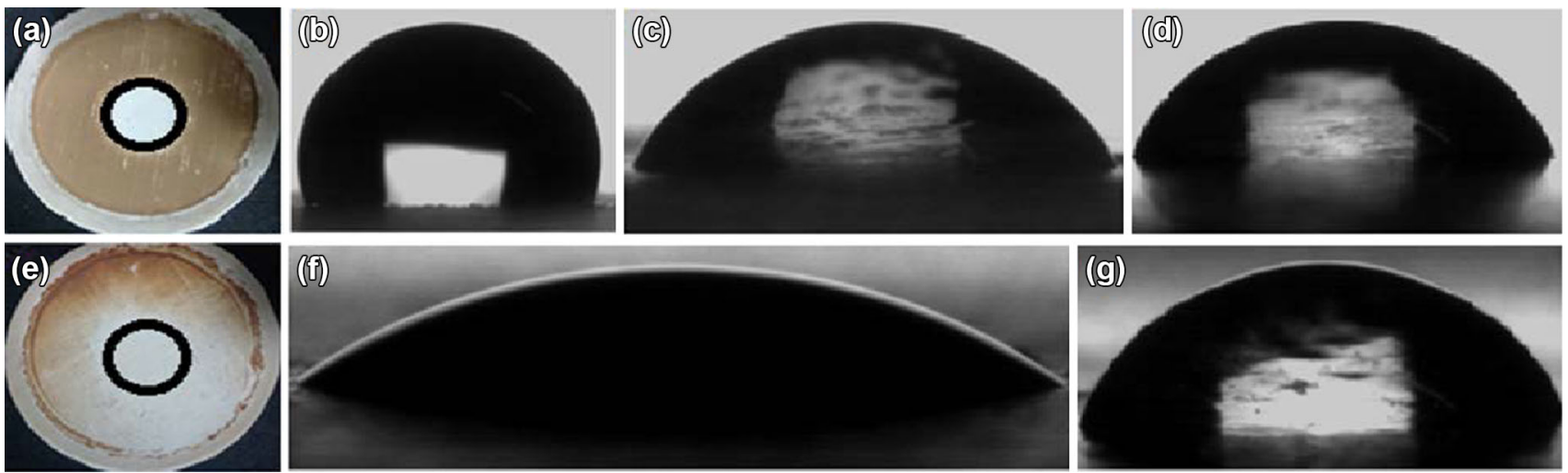

Fig. 9 Effect of addition of PAA to field water on membrane surface and hydrophilicity: feed containing no PAA a fouled membrane, b droplet shape in the drak part of the fouled membrane, c droplet shape at the centre part of the fouled membrane; feed containg PAA

d droplet shape on the pristine membrane suraface e fouled membrane, $\mathbf{f}$ droplet shape in the dark part of the fouled membrane, g droplet hape at the centre of the fouled membrane 


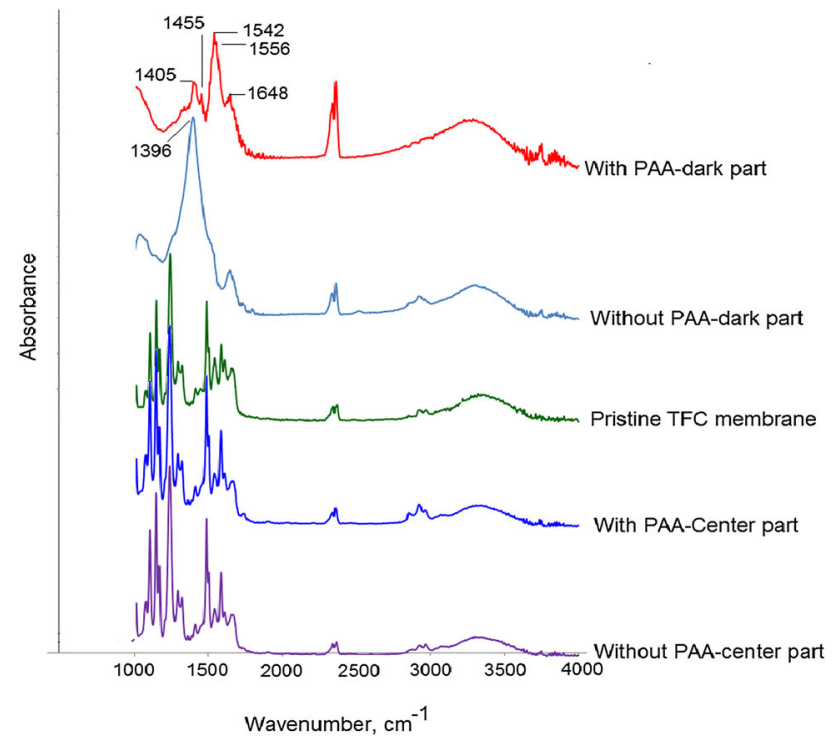

Fig. 10 IR spectra of pristine and fouled membranes surface after $60 \mathrm{~h}$ of filtration

membrane. IR spectra were recorded at different positions of fouled as well as pristine membrane samples (Fig. 10). The IR spectra of fouled membrane samples recorded at the center position of the membrane discs (position inside the circle as shown in Fig. 9a and e) irrespective of the fact whether PAA acid was added to the feed or not were found to be identical with the IR spectrum of the pristine membrane. This ensures that no fouling took place at the center of the membrane disc. Contact angle data support this observation. The IR spectrum of fouled membrane dark parts differs from the same when PAA was added to feed. When PAA was added to feed, the characteristic IR peaks at 1405 and $1556 \mathrm{~cm}^{-1}$ represent, respectively, the symmetric and antisymmetric stretching frequencies of carboxylate ion $\left(\mathrm{COO}^{-}\right)$and at $1455 \mathrm{~cm}^{-1}$ the stretching frequency of $\mathrm{CH}_{2}$ group indicating deposition of polyacrylic acid (Kirwan et al. 2003) on membrane surface. Since PAA is hydrophilic in nature (Carroll et al. 2002), the deposition of the same on membrane surface enhanced membrane hydrophilicity as indicated by contact angle value. Peaks at 1542 and $1648 \mathrm{~cm}^{-1}$ are due to amide II and amide I stretching frequency, respectively, and are characteristics of thin film composite polyamide membrane used in this study (Saha and Joshi 2009). When PAA was not added to feed, the nature of deposition on the membrane surface was different. Only one peak was observed in $1300-1600 \mathrm{~cm}^{-1}$ region. The peak at $1396 \mathrm{~cm}^{-1}$ represents symmetric stretching of $\mathrm{CO}$ of unionized carboxylic acid. Naidja et al. (2002) reported a similar IR peak in fulvic acid fraction extracted from soil exposed to high $\mathrm{CO}_{2}$ and nitrogen fertilization. Therefore, in the present study, the observed peak at $1396 \mathrm{~cm}^{-1}$ may be attributed to the humic acid fraction of field water.

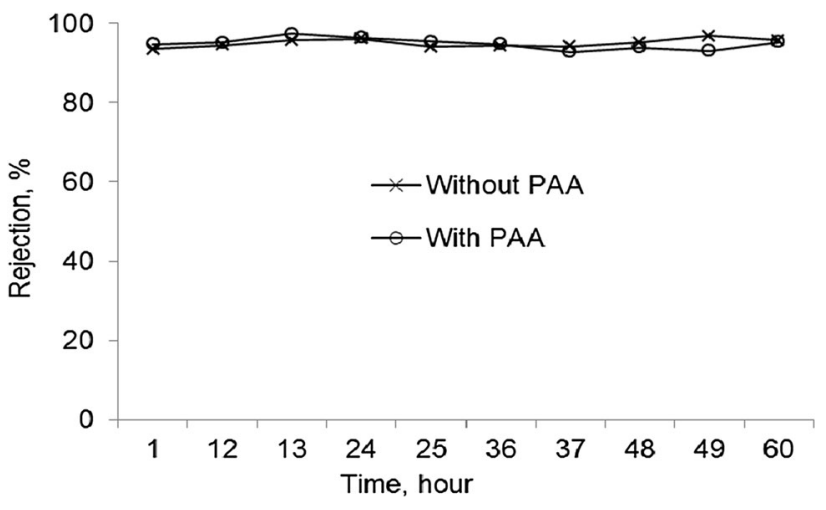

Fig. 11 Diuron rejection by membrane; feed contains diuron (2 ppm), PAA (100 ppm) in ultrafiltered field water

Use of antiscalant polyaspartic acid was reported to reduce reverse osmosis membrane fouling by humic acid significantly (Yang et al. 2010). Polyaspartic acid forms water soluble polyaspartic acid-Ca-humic acid complex and thereby neutralizes membrane fouling potential of humic acid and $\mathrm{Ca}^{2+}$ ion both. The metal ion binding capacity of PAA is reported earlier (Volchek et al. 1993). At high $\mathrm{pH}$, the deprotonated carboxyl groups of PAA form complex with divalent cations. If the solubility product of PAA-Ca/Mg complex exceeds precipitation may occur as observed in the present case. Choe et al. (1986) reported high rejection of PAA at low $\mathrm{H}^{+}$ concentration and at high cation concentration when PAA was ultrafiltered in the presence of $\mathrm{Cu}^{2+}$ ions. Authors proposed that at high cation concentration and at low $\mathrm{H}^{+}$ions concentration, the stretched and rigid conformation PAA might have changed the solubility of the complex in aqueous solution resulting in high rejection. Low concentration or the absence of free cations decreases charge shielding effect and increases solubility of NOM as discussed in previous sections. All these effects subsequently discouraged membrane fouling. Therefore, low membrane fouling by use of PAA as observed in this study is certainly due to reduction in free cation concentration due to formation of PAA-Ca/ $\mathrm{Mg}$ complex. Enhancement in membrane hydrophilicity as a result of PAA deposition on membrane surface might have been an additional support to membrane flux.

Finally diuron rejection remained consistently around $95 \%$ with some exceptions throughout the experiment irrespective of the fact whether PAA was added or not to feed. Feed and permeate samples were analyzed everyday for diuron content at the beginning and at the end of 12-h filtration experiment. Figure 11 presents trend in diuron rejection by membrane during $60 \mathrm{~h}$ of ultrafiltered field water filtration. This also supports our earlier observation that diuron rejection was uninfluenced by the presence of humic acid. 


\section{Conclusion}

Pesticides like diuron can be removed from agriculture field water by reverse osmosis membrane with minimum flux decline for economic operation of the filtration process. In the long-run operation, a steady permeate flux could be realized with high diuron rejection. Filtration of pesticides from field water suffers severe membrane fouling due to the composition of field water. Field water contains natural organic matter (NOM), divalent cations and may also contain microorganism. Membrane fouling is mainly caused by the natural organic matter, divalent cations present in field water. Diuron rejection was uninfluenced by the membrane fouling. Membrane fouling may be controlled by taking different feed pretreatment strategies suitable for arresting divalent cations since fouling potential of NOM like humic acids are promoted by the presence of these ions. Addition of ethylenediaminetetraacetic acid (EDTA) and polyacrylic acid (PAA) in feed effectively arrests membrane fouling by capturing free divalent cations. Steady membrane flux and uncompromised diuron rejection could be realized using PAA in field water. Membrane biofouling is another major cause of membrane performance decline observed during pesticide filtration. Pretreatment of field water using ultrafiltration membrane essentially prevents microbial contamination of feed water. Pre-filtration of feed significantly improved membrane performance during pesticide filtration.

Acknowledgments Authors are grateful to SERB, Department of Science and Technology, India for research funding (SERB/F/1599/ 2013-14) and Council of Scientific Industrial Research, New Delhi for support. Authors also acknowledge Miss. Richa Amiya for her assistance during microbial growth analysis.

Open Access This article is distributed under the terms of the Creative Commons Attribution 4.0 International License (http:// creativecommons.org/licenses/by/4.0/), which permits unrestricted use, distribution, and reproduction in any medium, provided you give appropriate credit to the original author(s) and the source, provide a link to the Creative Commons license, and indicate if changes were made.

\section{References}

Agbekodo KM, Legube B, Dard S (1996) Atrazine and simazine removal mechanisms by nanofiltration: influence of natural organic matter concentration. Water Res 30:2535-2542

Ahmad A, Tan L, Shukor SA (2008) The role of $\mathrm{pH}$ in nanofiltration of atrazine and dimethoate from aqueous solution. J Hazard Mater 154:633-638

Al-Amoudi AS (2010) Factors affecting natural organic matter (NOM) and scaling fouling in NF membranes: a review. Desalination 259:1-10
Benitez FJ, Acero JL, Real FJ, Garcia C (2009) Removal of phenylurea herbicides in ultrapure water by ultrafiltration and nanofiltration processes. Water Res 43:267-276

Boussahel R, Bouland S, Moussaoui K, Montiel A (2000) Removal of pesticide residues in water using the nanofiltration process. Desalination 132:205-209

Boussahel R, Montiel A, Baudu M (2002) Effects of organic and inorganic matter on pesticide rejection by nanofiltration. Desalination 145:109-114

Campo J, Masiá A, Blasco C, Picó Y (2013) Occurrence and removal efficiency of pesticides in sewage treatment plants of four Mediterranean River Basins. J Hazard Mater 263:146-157

Carroll T, Booker N, Meier-Haack J (2002) Polyelectrolyte-grafted microfiltration membranes to control fouling by natural organic matter in drinking water. J Membr Sci 203:3-13

Cho J, Amy G, Pellegrino J (1999) Membrane filtration of natural organic matter: initial comparison of rejection and flux decline characteristics with ultrafiltration and nanofiltration membranes. Water Res 33:2517-2526

Choe T, Masse P, Verdier A, Clifton M (1986) Membrane fouling in the ultrafiltration of polyelectrolyte solutions: polyacrylic acid and bovine serum albumin. J Membr Sci 26:17-30

Cyna B, Chagneau G, Bablon G, Tanghe N (2002) Two years of nanofiltration at the Méry-sur-Oise plant, France. Desalination 147:69-75

Dalton SK, Brant JA, Wiesner MR (2005) Chemical interactions between dissolved organic matter and low-molecular weight organic compounds: impacts on membrane separation. J Membr Sci 266:30-39

Devitt E, Ducellier F, Cote P, Wiesner M (1998) Effects of natural organic matter and the raw water matrix on the rejection of atrazine by pressure-driven membranes. Water Res 32:2563-2568

Drewes JE, Xu P, Bellona C, Amy G, Kim TU, Adam M, Heberer T (2004) Rejection of emerging organic micropollutants in nanofiltration/reverse osmosis membrane applications. Proceedings of the Water Environment Federation 2004: 77-96

Drews A (2010) Membrane fouling in membrane bioreactorscharacterisation, contradictions, cause and cures. J Membr Sci $363: 1-28$

Field JA, Reed RL, Sawyer TE, Martinez M (1997) Diuron and its metabolites in surface water and ground water by solid phase extraction and in-vial elution. J Agric Food Chem 45:3897-3902

Hao Y, Moriya A, Maruyama T, Ohmukai Y, Matsuyama H (2011) Effect of metal ions on humic acid fouling of hollow fiber ultrafiltration membrane. J Membr Sci 376:247-253

Hong S, Elimelech M (1997) Chemical and physical aspects of natural organic matter (NOM) fouling of nanofiltration membranes. J Membr Sci 132:159-181

Kirwan LJ, Fawell PD, van Bronswijk W (2003) In situ FTIR-ATR examination of poly (acrylic acid) adsorbed onto hematite at low pH. Langmuir 19:5802-5807

Mehta R, Brahmbhatt H, Saha N, Bhattacharya A (2015) Removal of substituted phenyl urea pesticides by reverse osmosis membranes: laboratory scale study for field water application. Desalination 358:69-75

Naidja A, Huang P, Anderson D, Van Kessel C (2002) Fourier transform infrared, UV-visible, and X-ray diffraction analyses of organic matter in humin, humic acid, and fulvic acid fractions in soil exposed to elevated $\mathrm{CO}_{2}$ and $\mathrm{N}$ fertilization. Appl Spectrosc $56: 318-324$

Newman A (1995) Ranking pesticides by environmental impact. Environ Sci Technol 29:324A-326A

Nilson JA, DiGiano FA (1996) Influence of NOM composition on nanofiltration. Am Water Works Assoc J 88:53

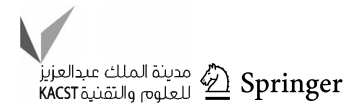


Plakas K, Karabelas A (2009) Triazine retention by nanofiltration in the presence of organic matter: the role of humic substance characteristics. J Membr Sci 336:86-100

Plakas KV, Karabelas AJ (2012) Removal of pesticides from water by NF and RO membranes-a review. Desalination 287:255-265

Saha N, Joshi S (2009) Performance evaluation of thin film composite polyamide nanofiltration membrane with variation in monomer type. J Membr Sci 342:60-69

Singh P, Rao A, Ray P, Bhattacharya A, Singh K, Saha N, Reddy A (2011) Techniques for characterization of polyamide thin film composite membranes. Desalination 282:78-86

Tang CY, Kwon YN, Leckie JO (2007) Fouling of reverse osmosis and nanofiltration membranes by humic acid-effects of solution composition and hydrodynamic conditions. J Membr Sci 290:86-94
Van der Bruggen B, Schaep J, Maes W, Wilms D, Vandecasteele C (1998) Nanofiltration as a treatment method for the removal of pesticides from ground waters. Desalination 117:139-147

Van der Bruggen B, Everaert K, Wilms D, Vandecasteele C (2001) Application of nanofiltration for removal of pesticides, nitrate and hardness from ground water: rejection properties and economic evaluation. J Membr Sci 193:239-248

Volchek K, Keller L, Velicogna D, Whittaker H (1993) Selective removal of metal ions from ground water by polymeric binding and microfiltration. Desalination 89:247-262

Yang Q, Liu Y, Li Y (2010) Humic acid fouling mitigation by antiscalant in reverse osmosis system. Environ Sci Technol 44:5153-5158 